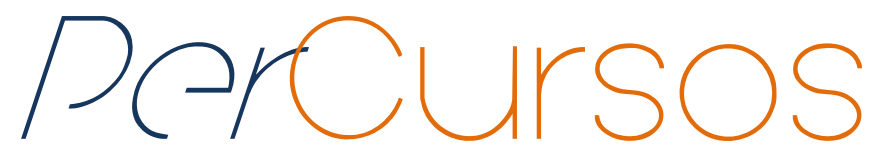

\title{
Racialização, subjetividades, arte e estética: um estudo de caso a partir da formação em psicologia
}

\section{Resumo}

Este texto propõe-se a discutir sobre tensionamentos entre arte, estética, decolonialidades, branquitude e negritude, a partir de um olhar feminista pós-estrutural e decolonial, para uma experiência de docência na primeira disciplina sobre raça da grade curricular da graduação em Psicologia em uma universidade pública do nordeste do Brasil. Toma como estudo de caso as vivências junto aos 45 alunos e alunas que puderam compartilhar de um debate teórico e epistemológico que se centrou na discussão sobre racismo, branqueamento, miscigenação, mito da democracia racial, branquitude, pactos de privilégio brancos, capitalismo e neoliberalismo, decolonialidades e as artes como formas de resistência local. Amparou-se na perspectiva de educação feminista participativa através de metodologias da arteterapia e de processos grupais, que têm as relações de poder e de voz/silenciamento no centro, utilizando-se de recursos de jogos teatrais, corporais e arteterapêuticos. Traremos excertos dos debates e deslocamentos realizados sobre as relações entre racialização e artes, através das idas a exposições/expressões artísticas em museus e em comunidades da cidade; e ao processo de construção da exposição "à flor/cor da pele" na confrontação com os processos de subjetivação e as políticas que tangenciam o campo Psi na formação de futuros profissionais menos colonizados.

Palavras-chave: Racialização. Subjetividades. Decolonialidades. Feminismos. Arte. Arteterapia.

\author{
Karla Galvão Adrião \\ Doutora em Ciências Humanas \\ pela Universidade Federal de \\ Santa Catarina - UFSC. \\ Professora da Universidade \\ Federal de Pernambuco - UFPE. \\ Brasil \\ galvaoadriao@gmail.com
}

\section{Mariana Borelli Rodrigues \\ Doutora em Psicologia \\ Universidade Federal de \\ Pernambuco - UFPE. \\ Psicóloga Clínica. \\ Brasil \\ mari.borelli@gmail.com}

\footnotetext{
Para citar este artigo:

ADRIÃO, Karla Galvão; RODRIGUES, Mariana Borelli. Racialização, subjetividades, arte e estética: um estudo de caso a partir da formação em psicologia. Revista PerCursos, Florianópolis, v. 20, n.44, p. 112 137, set./dez. 2019.
}

DOI: $10.5965 / 1984724620442019112$

http://dx.doi.org/10.5965/1984724620442019112 


\title{
Racialization, subjectivities, art and aesthetic: a case study based on vocational training in psychology
}

\begin{abstract}
This paper aims to discuss the tensions between art, aesthetics, decolonialities, whiteness and blackness, from a post structural and decolonial feminist look, for a teaching experience in the first discipline concerning race of the undergraduate Psychology curriculum in a federal university of northeastern Brazil. It takes as a case study the experiences with the 45 students who could share a theoretical and epistemological debate that focused on the discussion about racism, bleaching, miscegenation, myth of racial democracy, whiteness, white privilege pacts, capitalism and neoliberalism, decolonialities and the arts as forms of local resistance. It was based on the perspective of participatory feminist education through art-therapy and group process methodologies that have power and voice/silencing relations at the core of it, using theatrical, body and therapeutical art resources. We will bring excerpts from the debates and travels on the relationship between racialization and the arts through trips to exhibitions/artistic expressions in museums and in the city's communities; the process of building exposure to "À flor/cor da pele" in the confrontation with the processes of subjectivation and the policies that tangent the Psy field in the formation of less colonized future professionals.
\end{abstract}

Keywords: Racialization. Subjectivities. Decolonized. Feminisms. Arts. Art-therapy. 


\section{Introduzindo nossos deslocamentos rumo ao debate}

A chamada para este dossiê considera que tenhamos um olhar crítico à colonialidade que perpassa a construção discursiva e material do que é tido como arte em nossa sociedade. Ao falarmos a partir do campo da Psicologia, lócus de nossas atuações e construção de conhecimento, temos ainda como desafio constante o deslocamento/desmanche da colonização desse campo e de seus efeitos nas produções de saberes e práticas sobre as subjetividades. Tais construções, historicamente, têm desconsiderado a questão racial como fundante das subjetividades forjadas pela modernidade. É a partir desse posicionamento e da busca pela desconstrução (ou destruição) da colonialidade na imbricação entre arte, subjetividades, racialização, Psicologia e Arteterapia que construímos este artigo, que se baseia em um estudo de caso referente à disciplina "Tópicos em Psicologia 1: Psicologia, raça e estética como resistência", ministrada por nós no âmbito da graduação em Psicologia de uma universidade pública do nordeste do Brasil, no ano de 2018.

Somos duas mulheres psicólogas, uma docente da universidade em questão e a outra doutoranda em psicologia da mesma universidade, ambas de racialização branca, inseridas no campo dos estudos feministas e decoloniais. Há muitos anos refletimos sobre a construção da suposta neutralidade da Psicologia, a partir do campo feminista pós-estrutural e, mais recentemente, passamos a questionar a colonialidade da mesma disciplina, construída a partir da modernidade e seus pressupostos capitalistas (e, posteriormente neoliberais), a qual só foi possível através da fundante divisão mundialmente hierárquica em raças, com a colonização das Américas. Em tal divisão, a brancura foi considerada como sinônimo de humanidade e ao não-branco foi atribuído o status de não-humano (LUGONES, 2014; QUIJANO, 2005). A essa divisão hierárquica se relacionam também outras, como a divisão colonialmente imposta de gênero, a qual atribui uma suposta superioridade aos homens e inferioridade às mulheres (LUGONES, 2014).

Tal construção moderno-colonial da Psicologia impôs às sociedades colonizadas teorias e práticas construídas a partir de um referencial eurocêntrico, que têm como base 
o homem-branco-abastado-cisheterossexual-cristão. Baseia-se na Europa como detentora master do saber, o que somente foi possível, como afirma Ramón Grosfoguel (2016), a partir de epistemicídios das produções de saberes não construídos por homens brancos europeus. Nesse sentido, a Psicologia vem historicamente coadunando com a prática brasileira de, através do embranquecimento da raça e do genocídio da população negra (NASCIMENTO, 2017), negar a fundante questão racial do país, fruto de sua colonização e da escravidão de negros(as) e indígenas, não atentando para essa dinâmica local e situada que constitui subjetividades negras marcadas por constantes negações e sofrimentos, e subjetividades brancas marcadas pelos privilégios materiais e simbólicos decorrentes da estrutura fundamentalmente racista desta sociedade.

Importante pontuar que as noções de produções de subjetividades já promovem um deslocamento dentro do campo Psi, que sai de um olhar individualista e liberal - que tem o indivíduo como instância máxima de uma "personalidade" interiorizada para um debate entre micro e macro políticas corporais, nas quais se conformam as subjetividades humanas. Estas, agora, não são mais instâncias cristalizadas, antes, tratam de processos perpassados por questões culturais, econômicas, coletivas e individuais (ROSE, 2011).

No que se refere especificamente às imbricações entre a Psicologia e o campo das relações raciais, há também transformações que acompanham o discurso racial sobre o(a) negro(a) ao longo de nossa história como "nação". Em fins do século XIX e início do século $X X$, o pensamento psicológico tinha o(a) negro(a) como “objeto da ciência" e “portador(a)" de características patologizantes, numa perspectiva natural/biológica'. Por volta da década de 1930, buscava-se politicamente a "identidade nacional" dos(as) brasileiros(as) e sua "positividade". Esse período é marcado pela visão "culturalista" das questões raciais ${ }^{2}$. Nele surgem os primeiros cursos de Psicologia Social no país e os estudos sobre diferenças, atitudes, estereótipos e preconceitos raciais - trazendo, portanto, uma perspectiva cultural, em contraponto à biologização da raça (SANTOS; SCHUCMAN; MARTINS, 2012). Após a década de 1970 e a abertura democrática no país, o

\footnotetext{
1 Marcada pela Escola Nina Rodrigues e seus estudos raciais deterministas.

2 Gilberto Freyre é um dos principais nomes da visão culturalista - sinalizando a miscigenação racial e a positividade desta para a identidade nacional. Mais adiante discorreremos novamente sobre este autor.
} 
pensamento Psi sobre raça ultrapassa a biologia e a cultura, passando a problematizar a raça como uma construção social que marca diferenças e impõe desigualdades e hierarquizações, no âmbito de relações de poder que constroem subjetividades e identidades negras e brancas. Nessa perspectiva, enquanto os(as) brancos são subjetivados e tidos(as) socialmente como referenciais de universalidade e humanidade, os sujeitos(as) negros(as) têm suas identidades e corporeidades negadas, constantemente marcadas pelo ódio racial e por múltiplas tentativas de branqueamento subjetivo e social (BENTO, 2002). Ainda que um campo incipiente e contra-hegemônico, cresce a concepção da Psicologia como responsável não apenas por "estudar" as relações raciais como "objeto" de conhecimento, mas como área primordial para uma luta antirracista (SCHUCMAN; MARTINS, 2017). Nesse sentido, a Psicologia não deve estar somente atenta às desigualdades, mas deve também desenvolver uma práxis que fortaleça a construção de identidades/subjetividades que se autorreconheçam enquanto negras em sua positividade e em suas possibilidades de bem-viver, bem como a construção de identidades/subjetividades brancas não produtoras e reprodutoras de privilégios e violências.

A discussão sobre processos de subjetivação no campo Psi também tem muito a receber de contribuição do campo das artes em geral, enquanto espaços de constituição de saberes que se fundam em processos de acesso às criatividades e a dispositivos que não necessariamente apelem a uma ideia dicotômica colonial de racionalidade/razão em oposição a emoção/sentimentos. Além disso, o espaço das artes, enquanto disparadoras de percepções e emoções subjetivas, pode proporcionar um debate importante sobre como e se os processos e produções artísticas podem se relacionar como o acesso a uma criticidade ética. Nesse sentido, diversos artistas ${ }^{3}$ vêm debatendo sobre o que consideram como a importância de trazerem em suas obras uma reflexão sobre desigualdades sociais, raciais, ambientais, de gênero, dentre outras. Provoca-se,

\footnotetext{
3 Dentre estes, citamos aqui alguns artistas que nos influenciam com sua produção e que serviram de exemplo nas aulas da disciplina em questão neste artigo: o movimento de mulheres feministas nas artes, chamado Guerrilla Girls; o trabalho do Chinês Ai Wei Wei, que discute em suas obras questões de desigualdades e tensões políticas, sociais e ambientais, relacionando as noções de arte e artivismo; e, um pouco mais distante temporalmente, ainda nas década de 1990, o artista plástico Frans Krajcberg, que ficou conhecido por trazer o debate sobre a tensão dos desmatamentos na Amazônia.
} 
portanto, uma fissura de visão das artes enquanto como "resistência", provocadoras de deslocamentos subjetivos naquelas pessoas com as quais se relaciona. As artes, nesses termos, são políticas e produzem saberes e poderes.

Cabe a crítica a uma compreensão da Arte, significante no singular, enquanto atravessada por relações de saber-poder centradas no norte do globo e marcada por uma maneira específica e dominante de compreensão dos elementos estéticos e de seus processos subjacentes. As artes contemporâneas (mas não apenas elas) deslocam as relações com os materiais expressivos e lócus/territórios de expressões tradicionais para localizações político-conceituais e performáticas, ocupando uma posição de descentramento importante, inclusive ao se relacionar com diversas expressões de demandas de identidades subalternizadas como as de classe-raça-sexualidades dissidentes. O termo artivismo (MEIRA, 2019), chega nesse contexto apontando a necessidade de ocupação da arte como expressão das decolonialidades. Assim, tanto as Psicologias quanto as Artes necessitam serem descolonizadas.

Atentamos, portanto, para a discussão sobre a relação entre colonialidades e artes, e a necessidade de descolonizar as artes, abrindo espaço para trabalhar com as mesmas como práticas de resistência local-global, de forma que resgatemos e nos apropriemos dos saberes ancestrais e locais que foram silenciados nas relações de colonialidade nas Américas ${ }^{4}$.

Como duas mulheres brancas detentoras de muitos dos privilégios de branquitude, entendemos que também cabe a nós questioná-los, desconstruí-los e/ou redistribuí-los. Ao acessar certos tipos de conhecimento (um de nossos privilégios) e permitirmo-nos sentir tocadas por ele, assumimos o compromisso ético de redistribuí-lo, ampliando a discussão racial na Psicologia, questionando o racismo cotidiano a nossa volta, buscando romper os pactos narcísicos de silêncio entre nós brancas/os (BENTO, 2002), e tomando o trabalho a partir das artes como processos de resistência e

\footnotetext{
${ }^{4}$ Aqui nos inspira em muito o trabalho da artista plástica brasileira Rosana Paulino, por trazer o debate da colonialidade através de relação de saber, de poder e do ser, discutindo em suas obras noções de ancestralidade da raça negra e gênero de maneira inspiradora e provocadora de muitos deslocamentos. A mesma foi trazida nas aulas da disciplina em questão, como exemplo. Mais informações em: www.rosanapaulino.com.br.
} 
(re)construção de subjetividades. Entendemos que, como afirma Maria Aparecida Bento (2002) ao discorrer sobre a branquitude brasileira, esse é um processo sempre em andamento, no qual necessitamos estar abertas a escutar, aprender e nos revisitar em nossas ações.

Dessa maneira, faz-se importante falarmos sobre o contexto de produção da disciplina antes de refletirmos sobre a mesma e sobre processos de colonizaçãodescolonização da arte. A primeira autora deste texto atuava, no ano de 2018, como coordenadora do curso de Psicologia em questão e, neste contexto, houve um conjunto de mobilizações por parte de estudantes negros e negras, denunciando e solicitando ações da coordenação do curso e gestão da universidade frente às denúncias de fraudes nas cotas raciais para entrada em cursos universitários. Tais denúncias levaram a intensos debates realizados entre estudantes, docentes e gestores/as sobre a invisibilização das questões raciais, das práticas racistas e dos exercícios de branquitude presentes na própria Psicologia e no curso em questão.

Diante disso, um dos encaminhamentos de toda essa mobilização foi a criação de uma disciplina sobre questões raciais na graduação em Psicologia. Visto que esse encaminhamento se deu já no final do semestre letivo, no qual boa parte dos/as docentes já estavam com seus horários fechados para o próximo semestre e, em conjunto com isso, a aproximação com a questão racial, decidiu-se que a própria coordenadora do curso ministraria a disciplina. A mesma convidou uma estagiária docente e mais três estudantes de graduação para comporem a equipe de construção e execução da matéria 5

Passamos $^{6}$, então, a dialogar sobre o que esperávamos dos encontros. para a disciplina. De antemão, gostaríamos que fosse uma disciplina pensada, de certa forma, coletivamente, não restrita aos nossos vieses e conhecimentos anteriores. Além disso,

\footnotetext{
${ }^{5}$ Aqui agradecemos a Arielson Marcello Alves do Nascimento, Dara Catarina Santos da Silva e Emmanuel Italo da Silva Santos, estudantes da graduação e integrantes de nosso núcleo de pesquisa (A Coletiva/LabEshu - Laboratório de Estudos da Sexualidade Humana), por caminharem conosco nessa jornada, nos assessorando em tantos momentos necessários.

${ }^{6}$ Voltamos a utilizar a terceira pessoa do plural no artigo, tendo em vista que nos parágrafos anteriores recorremos a um recurso linguístico de "contar uma história sobre nós mesmas", em terceira pessoa do singular, como se uma narradora aparecesse para desenvolver essa estratégia discursiva momentânea.
} 
tendo em vista a formação de uma das autoras em Arteterapia ${ }^{7}$, e a concepção de ambas na potência que a arte tem em produzir/deslocar subjetividades, desejávamos também que a arte como elemento de re-existência fosse central na disciplina. Dialogamos previamente com diversas pessoas inseridas no campo do debate racial: professores(as), profissionais da Psicologia, militantes, os(as) quais nos sugeriram uma série de ideias, textos e obras. Por fim, a cadeira teve como objetivo apresentar os estudos sobre raça e racismo no Brasil como um campo da Psicologia, com ênfase no debate sobre colonialidade e decolonialidade, tendo a arte como resistência.

A disciplina foi dividida em dois módulos, em que o primeiro foi de cunho mais teórico, enquanto que no segundo houve presença de pessoas convidadas (pesquisadores/as e/ou militantes) com expertise em temáticas pertinentes ao campo. Versou-se sobre: mito da democracia racial, decolonialidade, branqueamento da raça, branquitude, efeitos sociais e subjetivos do racismo, relações entre raça e classe social, feminismos negro e decolonial. As temáticas trabalhadas com pessoas convidadas foram: Psicologia, ações afirmativas e políticas de cotas; redução de danos e encarceramento; raça e saúde mental; panorama das pesquisas sobre raça na pós-graduação e artivismo e raça.

Atividades artísticas e arteterapêuticas foram realizadas e facilitadas por nós (e/ou pessoas convidadas) durante todo o decorrer da disciplina. Além disso, tivemos atividades externas à sala de aula, como ida a duas exposições, além de uma atividade político-artística realizada em um bairro periférico do Recife. A disciplina pouco a pouco foi se encaminhando para uma culminância de produção de uma exposição artística na

\footnotetext{
7 Estamos de acordo com Angela Phillipini (1998, p.2) quando discorre sobre a Arteterapia: "Existem inúmeras possibilidades de conceituar arteterapia. Uma delas é considerá-la como um processo terapêutico decorrente da utilização de modalidades expressivas diversas, que servem à materialização de símbolos. Essas criações simbólicas expressam e representam níveis profundos e inconscientes da psique, configurando um documentário que permite o confronto, no nível da consciência, destas informações, propiciando "insights" e posterior transformação e expansão da estrutura psíquica. Uma outra forma de dizer, poderá ser simplesmente terapia através da Arte. Embora seja necessário localizar com muito cuidado, de que é mesmo que se fala, quando se emprega a palavra arte, pois neste contexto, arte referencia - o processo expressivo - da forma mais ampla e abrangente que se pode empregá-lo. Não haverá assim, a preocupação estética e com técnicas, sendo privilegiada a possibilidade de expressão e comunicação e o resgate e ampliação de possibilidades criativas. O universo dominante em arteterapia é o da sensorialidade e da materialidade: texturas, cores, formas, volumes, linhas. E integrar-se e movimentar-se nesse universo requer atenção e preparo".
} 
qual se continham as obras feitas pelas(os) estudantes, durante o semestre, ao se conectarem com as diversas temáticas e questões epistemológicas tratadas. A exposição foi organizada pelas(os) mesmas(os), que se dividiram autonomamente em seu processo de curadoria. Discorreremos mais detalhadamente sobre esses percursos artísticos adiante.

\section{Arte e (é) política: confrontações entre racismo e branquitude nos}

\section{percursos artísticos da disciplina}

Tomando a perspectiva de que a construção de conhecimento é corporificada (HARAWAY, 1995), trabalhamos na disciplina a partir de um deslocamento da ideia de "apreensão" para a compreensão de que realizávamos uma "experimentação" do conhecimento (ADRIÃO, 2015, 2019; FINE et al., 2006; FREIRE, 1999). O uso das metodologias participativas ${ }^{8}$ e de elementos artísticos/arteterapêuticos como proposta teórico-metodológica foram pedra angular para a construção do conhecimento sobre raça. Sabemos que compreensões artístico-estéticas não estão dissociadas da colonialidade e do eurocentrismo. No entanto, as entendemos como um processo decolonial, valorizando-se contextos locais de produção de saberes e resistências. Compreendemos e produzimos arte relacionando esse processo de produção com as epistemes feminista pós-estrutural e decolonial. O processo e não o produto final de produção artística torna-se centro, sendo esse o foco para onde emerge todo o esforço criativo. Apesar disso, foram construídos projetos individuais e/ou coletivos para comporem em formato de instalação, de livros do(a) artista, de colagens e de pinturas com produção de estêncil, a exposição final da disciplina. Entendíamos que o processo de

\footnotetext{
${ }^{8}$ Consideramos metodologias participativas através de uma gama de estudos em pesquisa-intervenção, que tomam os conceitos de pedagogia da autonomia e de realidade concreta de Paulo Freire como fundamentos básicos. A perspectiva feminista pós-estrutural na qual nos embasamos também dialoga com pedagogias feministas que incluem nesse debate as questões de poder, e suas relações de desigualdades de classe, raça e gênero. Importante evocar a questão da participação como elemento central e o uso de distintos métodos que incentivem uma participação de todas as pessoas envolvidas no processo grupal. Dessa forma, lança mão de métodos corporais, de jogos teatrais e de elementos arteterapêuticos de forma a tentar abrir outras possibilidades de expressão que não sejam tão cunhadas pela fala. Isso porque a fala traz uma racionalidade, e, relações de poder cristalizadas podem reiterar o silenciamento de quem já silencia cotidianamente por questão de distintas desigualdades (ADRIÃO, 2014; ADRIÃO, 2019).
} 
produção era o momento de grande relevância, e, tendo isso em mente, ao decidirmos em conjunto - professoras e alunas(os) - por construir uma exposição com visitação de pessoas da Universidade e da comunidade, o foco processual manteve-se através da decisão de construir uma mediação das obras. Além disso, muitas obras eram em formato interativo, nas quais o processo continuava durante os dias de exposição.

Compreendemos as expressões artísticas como "coisa política” e a política como estética, tal como Jaques Rancière. Ao afirmar que "seu gesto pertence à constituição estética da comunidade e se presta, acima de tudo, a alegorizar essa constituição [...] Por constituição estética deve-se entender aqui a partilha do sensível que dá forma à comunidade" (RANCIÈRE, 2017, p. 7). Nesse sentido, as artes e suas expressões estéticas atuam como ações discursivas comunitárias como formas de resistência e existência em relação às normas e hegemonias. As artes possibilitam ainda fundamentos da constituição de uma episteme das subjetividades com vistas a um processo terapêutico. Assim sendo, utilizamos na disciplina elementos e recursos da Arteterapia para tratar das questões de opressão e privilégio, e das produções subjetivas atreladas, trabalhando de forma teórico-vivencial durante todas as aulas, que tinham duração de quatro horas semanais, permitindo essa maneira de atuação (ADRIÃO, 2019; LOPES; 2012; PHILIPPINI, 2011; SILVEIRA, 2015).

Foi a partir dessas compreensões, portanto, que durante todo o processo da disciplina mesclaram-se os conteúdos teóricos com os elementos artísticos e formas de expressões estético-políticas (RANCIÈRE, 2017). Considerando a potência das relações entre imagens e produção de significados, a construção de expressões artísticas se deu de forma gradual e paulatina, visando permitir, através das produções, o acesso a imagens e conteúdos do inconsciente (ADRIÃO, 2019; SILVEIRA, 2015) e suas relações com marcadores de desigualdades, vivências de opressão e de privilégios, frente às questões raciais.

Nesse sentido, a introdução do material a ser disponibilizado às(aos) estudantes também se deu de forma gradual, apresentando-se inicialmente materiais plásticos mais palatáveis, tais como recortes de imagens de revistas, lápis de cor, giz de cera; e então progressivamente foram introduzidas tintas aquareladas, carvão e giz de quadro branco; 
tecidos e materiais de costura, materiais de plástico e perfuro-cortantes para produção de estêncis, além dos recursos corporais através de jogos teatrais e da performance (ADRIÃO, 2019; BOAL, 2007, 2009; PHILLIPINI, 2011).

Foram trabalhados três momentos metodologicamente demarcados pelo modelo pedagógico e arteterapêutico de trabalho com grupos: um primeiro, individual, centrado na abertura e estímulo ao processo criativo de cada interagente, através de trabalho gradual com materiais expressivos; e um segundo mais grupal, no qual os recursos artísticos são catalizadores das expressões temáticas e/ou conceituais (ADRIÃO, 2019; PHILIPPINI, 2011). Mesclamos esse processo com as metodologias feministas participativas, que visam apropriação e consolidação paulatina do processo participativo, atentando para as relações de poder e desigualdade, além do silenciamento que pontua quem pode falar e quem tradicionalmente cala em um grupo (MCCARTHY; ADRIÃO, 2001; SPIVAK, 2010).

O terceiro momento no processo pedagógico de inspiração arteterapêutica trata do processo autogestivo, o qual foi trabalhado através de um arremate de muitos desejos, chegando-se à ideia de concepção e culminância da disciplina em uma exposição artística. Os/as 45 alunos/as da turma organizaram-se de forma autônoma entre aqueles/as que seriam organizadores/as e curadores/as e aqueles/as que realizariam projetos artísticos para a mesma.

\section{Percursos-inspirações em espaços artísticos da cidade: contrapontos}

\section{entre os territórios do museu e da periferia}

Dois momentos de visita aos espaços artísticos da cidade foram muito importantes para a produção de deslocamentos na disciplina e no processo de ensino-aprendizagem sobre questões raciais. O primeiro momento de visitação, ainda no período inicial da disciplina, foi à exposição intitulada "Raça, classe e distribuição de corpos", no Museu do Homem do Nordeste, localizado em um bairro de classe média e alta da cidade. $\mathrm{O}$ segundo momento aconteceu no Alto do Pereirinha, localizado em um bairro de periferia da mesma cidade, no qual fomos assistir uma roda de poesia do grupo Recital Boca no 
Trombone. Em relação aos deslocamentos produzidos, o primeiro deles trata da territorialidade; o segundo das concepções de arte exposta em um espaço tradicional um museu - em relação à arte nas ruas; o terceiro trata de quem concebe cada uma dessas produções e os públicos que as acessam.

O Museu do Homem do Nordeste, hoje ligado à Fundação Joaquim Nabuco e ao Ministério da Educação, foi criado em 1979 pelo sociólogo Gilberto Freyre através da fusão de outros três museus - o Museu de Antropologia (1961-1979), o Museu de Arte Popular (1955-1966) e o Museu do Açúcar (1963-1977). Fica localizado em um bairro que abriga antigos casarões coloniais em conjunto com contemporâneos prédios arranhacéus. O bairro, assim como seu vizinho Apipucos (onde ficam a Fundação Gilberto Freyre - no qual o sociólogo residiu - e a Fundação Joaquim Nabuco), traz nas denominações dos edifícios e comércios a presença da colonialidade. Alguns prédios e estabelecimentos comerciais são denominados de "Casa-Grande" "Engenhos" e, inclusive, "Senzala".

A exposição "Raça, classe e distribuição dos corpos" trazia obras de artes diversas (vídeo-arte, fotografias, pinturas a óleo, instalações) de artistas brasileiros e brasileiras que faziam uma leitura de raça e classe marcada por seu contexto histórico-cultural. Algumas provocavam essa leitura intencionalmente, outras reiteravam certos lugares de desigualdade e o olhar crítico dependia do/a visitante. As obras provocavam reflexões sobre os lugares físicos e simbólicos ocupados pelas pessoas brancas e negras, em diferentes momentos históricos. Um dos vídeos-arte apresentados na exposição trazia um tensionamento frente às relações de raça e classe no trabalho doméstico da própria moradia de Gilberto Freyre, mostrando falas e rotinas de trabalhadores/as de sua casa. Nesse sentido, a exposição ora trazia tal crítica às questões das desigualdades raciais, ora reiteravam-na.

Após vermos as obras, sentamos em roda com os/as estudantes e mediadores/as da exposição para dialogarmos sobre a mesma, a partir da ótica do pensamento decolonial, uma das temáticas a ser problematizada na disciplina. Os/as estudantes então trouxeram seus olhares e impressões. Dentre elas, estava a questão de a curadoria ser feita por um homem branco, trazendo consigo o olhar racializado a partir de uma perspectiva branca. A turma, então, questionou as relações de saber/poder, tensionando 
os privilégios materiais e simbólicos da branquitude: o acesso ao ensino superior, aos mais altos postos de trabalho, às ‘obras de arte’ e, portanto, às produções discursivas que tais privilégios trazem consigo. O que pretendemos aqui não é desmerecer a importância do trabalho de tal pesquisador, mas apresentar a importância do questionamento dos/as estudantes, o que provoca a reflexão sobre abertura ao discurso dos saberes subalternos, negritando assim as diferenças e desigualdades entre quem fala e quem cala (SPIVAK, 2010).

Outra questão problematizada por nós no debate dizia respeito à própria denominação do museu - trazendo questões sobre linguagem, discurso e relações de poder e colonialidade. Uma denominação não se trata somente de palavras escolhidas arbitrariamente, mas traz, ao contrário, consigo, valores e concepções de mundo e humanidade. Diante disso, os(as) estudantes questionaram: quem seria "o homem" do Nordeste? Além da universalização da palavra homem encobrindo e invisibilizando as mulheres, no geral, o termo se faz, então, profundamente colonial, trazendo consigo uma concepção de humanidade unívoca. Pensando que o museu foi fundado por Gilberto Freyre, um dos responsáveis pelas construções do mito da democracia racial no país, o nome do museu traz consigo então a profunda marca, aprofundada pelo sociólogo, da imagem do homem miscigenado. Afinal, Casa Grande e Senzala, obra mais difundida do autor, traz as relações de escravidão das pessoas negras e indígenas, mostrando um processo de miscigenação passivo, romantizado e não fundado em profundas violências e desumanização das pessoas não-brancas". A suposta "humanidade unívoca" do "homem do nordeste" traria então consigo os processos de embranquecimento forçados no processo de miscigenação. Como nos diz Abdias do Nascimento (2017), o

\footnotetext{
${ }^{9}$ Cabe dizer que Gilberto Freyre é tido como um dos responsáveis pela criação do mito da Democracia Racial no Brasil, visto sua ênfase nas relações harmônicas e conciliatórias entre as diferentes raças acabando por romantizar diversos aspectos da escravidão e das hierarquias raciais. Ainda que pese a importância dessa crítica, vale ressaltar, no entanto, que no contexto de produção de sua obra estavam amplamente disseminadas no Brasil teorias raciais de cunho eugenistas e biologicistas pautadas na inferioridade do negro brasileiro e uma ênfase na necessidade do "branqueamento" no Brasil. Em tais teorias deterministas, a mestiçagem era algo a ser evitado, condição de degenerescência (SCHWARCZ, 2012). Por volta da década de 1930, um conjunto de estratégias políticas e culturais passam a considerar a mestiçagem como símbolo de identidade nacional. Nessa direção, a obra de Freyre tem uma importância fundamental para um deslocamento epistêmico (que rebate o biologicismo e passa a enfatizar o culturalismo) frente às relações raciais.
} 
embranquecimento da população se traduz como um projeto político de extermínio da raça negra, através dos estupros das mulheres negras em conjunto com a intensa valorização da vinda de imigrantes europeus ao Brasil.

Além disso, podemos problematizar, através da denominação do museu, uma determinada postura imperialista no que concerne ao estado no qual o mesmo está territorialmente, e deste frente ao nordeste do Brasil. Para nós, fica a pergunta: o que caracterizaria e unificaria "o homem" nordestino a ponto de existir um museu, nesse estado, para o mesmo? Talvez, uma pergunta anterior seja necessária: o que caracterizaria e unificaria o próprio "homem" pernambucano a ponto de se concentrar, em sua capital, tal museu, visto a imensa diversidade cultural e territorial do próprio estado? Estariam, nesse sentido, contemplados, "os homens" do litoral, do agreste e do sertão de Pernambuco?

Refletir sobre arte nos museus trata também de discutir sobre posições de valor e reconhecimento compartilhado junto às obras produzidas e escolhidas para ali estarem. Aqui cabe o questionamento sobre quem produz, quem reconhece e a quem se destina/compartilha a arte. O território da rua e as artes produzidas nesses contextos vêem deslocando as próprias noções sobre Arte e estética, inspiradas nas artes conceituais, e nas manifestações artísticas posicionadas, marcas das artes contemporâneas que se apresentam como resistência ao status quo e à colonialidade.

Após a visita ao Museu, em sala de aula foram trabalhados conteúdos reflexivos das discussões travadas anteriormente. Particularmente, as questões sobre branquitude e subjetividades negras se fizeram presentes a partir da construção de histórias coletivas em duplas e depois em pequenos grupos. Essas histórias foram estimuladas através de excertos das obras de Franz Fanon, e através de estímulos para que fossem construídas bricolagens de histórias. Em um segundo momento, essas mesmas histórias foram dinamizadas através de técnicas do teatro do oprimido e de jogos participativos e de ensaio (BOAL, 2007; MCCARTHY; ADRIÃO, 2001). Performances foram construídas e apresentadas em sala de aula. Relatos posteriores às apresentações apontavam para um reconhecimento dos próprios privilégios, por parte de jovens brancas que perceberam que poderiam transitar como futuras psicólogas com menos (ou nenhum) preconceitos 
por parte de quem buscava os serviços de psicologia, "pelo simples fato de não ser negra e portanto, não ser vista como incapaz de ocupar certas profissões como a Psicologia" (Estudante 1. branca, de classe média alta, 26 anos, 2018, informação oral).

As(os) alunas(os) produziram, processualmente, obras de artes, a partir da arteterapia e dos jogos teatrais, a respeito dessas tensões. O uso de carvão vegetal e de giz branco em papel kraft, por exemplo, estimulou o debate em torno de sombra e luz e de como elementos subjetivos estão presentes nos discursos que reiteram o mito de uma democracia racial. Em contrapartida, a costura coletiva de bonecas Abayomis, trouxe o resgate da ancestralidade negra em sua relação com história, gênero e arte. Esses elementos apoiaram também a preparação do grupo para a ida a uma segunda exposição artística, dessa vez, fora dos espaços instituídos de museus e galerias, através da visita ao Evento do grupo Boca do Trombone.

O grupo Recital Boca no Trombone se reúne, principalmente, em um campo de futebol com piso de areia batida, em um Morro, localizado em um bairro da zona norte da cidade. Pensando, então, o deslocamento frente à territorialidade, passamos de um bairro de concentração classe média alta e branca, com casarões e prédios tidos como modernos, para um bairro periférico, onde em boa parte prevalece a favelização. Se o museu garante "conforto" para quem o visita, no espaço do morro nos deparamos com as fragilidades de infra-estrutura e precariedade para a moradia local.

Tais deslocamentos nos permitem, inclusive, questionar a noção de conforto: para quem é confortável estar no museu e para quem é confortável estar no campo de futebol no alto de um morro na periferia? O conforto diz respeito à certa familiaridade com o local, com a representatividade de pessoas nesse território, com os lugares ocupados pelos corpos que se parecem com aquele/a que se sente, ou não, confortável. Nesse sentido, migrar pelos dois espaços de visitação, permitiu ainda um processo de “estranhamento do familiar" (VELHO, 1978) e o encontro com as noções de ocupação dos espaços urbanos enquanto ações de resistência frente ao modelo capitalista e neoliberal, que individualiza e de(s)compõe em descontinuidades as relações de coletividade e solidariedade. As artes têm um papel de abertura e reconhecimento de 
valores ancestrais e atuais, promovendo uma bricolagem de conceitos e sentimentos que se coadunam nos processos de produção artística (RANCIÈRE, 2017).

Os encontros do grupo Boca no Trombone acontecem à noite e, no dia de nossa ida, contamos com a presença de um número bastante inferior de estudantes da disciplina, o que de antemão nos faz pensar sobre a disponibilidade de boa parte dos/as alunos/as para a visita aos espaços periféricos da cidade, inclusive em se permitir esses processos de estranhar o familiar e se familiarizar com o estranho, e de aproximar-se de modelos solidários de ocupação da cidade, através da arte.

O Recital Boca no Trombone é protagonizado por mulheres negras de periferia e conta com a presença da juventude, também em maioria negra do bairro em questão e de bairros vizinhos, que se expressa através das linguagens do Hip Hop. Há uma intencionalidade na produção artística como espaço de resistência e sobrevivência da juventude. O grupo, através da arte por meio de rodas de poesia e de batalhas de MC's, denuncia as condições de violência e invisibilidade da população negra nas periferias, ressaltando as violências sofridas pelas mulheres negras, donde parece que subjaz a concepção de que uma luta feminista deve ser fundamentalmente antirracista, e viceversa. Para o grupo que se encontra, há uma consciência de raça e classe, um fortalecimento da negritude e a expressão artística se dá através de um resgate à ancestralidade e fortalecimento de suas expressões atuais.

Experimentar esses dois espaços como corpos e corporalidades de alunos e alunas brancos e negros, de um curso de graduação de uma universidade pública do nordeste do Brasil trouxe a possibilidade de correlacionar conceitos, epistemes e metodologias com a realidade concreta (FREIRE, 1999) e os processos e efeitos de sentidos correlatos.

A partir das relações entre essas vivências e as da sala de aula, foram produzidos projetos artísticos com usos de diversos materiais expressivos e de performances e técnicas de teatro, visando uma exposição como culminância de todas as aulas, que foi aberta ao público universitário e comunitário da localidade, por dois dias. A mesma passou também a fazer parte de um encontro maior, denominado de "I Encontro de Psicologia na Universidade: Formação, Pesquisa e Práticas”. No mesmo, além de 
apresentações de trabalhos científicos, havia o espaço para exposições, performances e instalações e outras expressões artísticas como artes plásticas, zines, desenhos, música e poesia. Todos(as) estudantes da disciplina participaram como coautores do processo da exposição. Essa também foi a primeira vez em que o curso de graduação em Psicologia assistiu e interagiu em uma exposição artística que trabalhava os conceitos de uma disciplina da grade curricular do curso $^{10}$. Contamos com a presença de cerca de 500 pessoas, entre trabalhadores(as) de serviços gerais, ascensoristas, pessoal da portaria, técnicos(as)-administrativos, professores da graduação e da Pós-Graduação em Psicologia, alunos dos cursos de Psicologia, Artes, Pedagogia, Serviço Social, História, Ciências Sociais, profissionais arteterapeutas, psicólogas e educadoras físicas, direção do Centro ao qual o curso de Psicologia está relacionado, além de alguns amigos(as) e familiares.

\section{À flor/cor da pele: a exposição e seus elementos ético-estético-}

\section{políticos}

As produções artísticas trabalhadas no processo da disciplina foram organizadas por um grupo de curadores/as, alunos e alunas da própria matéria. Para tanto, os(as) estudantes se dividiram de maneira coletiva e autônoma entre si, como dito anteriormente. Foi feita a escolha das obras (optou-se por colocar todas as obras que os autores/artistas autorizassem), e a forma de apresentação e disposição em categorias. As obras foram montadas pelos/as artistas junto à equipe de produção e dispostas numa sala com música e ambiente climatizado. Em torno de 20 produções, entre pinturas em carvão, giz, e pastel; colagens; instalações e livros dos(as) artistas.

\footnotetext{
${ }^{10}$ Antes disso, iniciativa similar ocorreu em meados dos anos 2000, quando o Diretório Acadêmico do curso, compreendendo a diversidade e pluralidade de expressões artísticas produzidas por estudantes, poderia ser compartilhada nos corredores e hall principal do andar do andar onde aconteciam as aulas do curso de Psicologia. O 'Vitrine Psi' contava com instalações que apresentavam artes plásticas e textos poéticos e de poesia. Também aconteceram apresentações e performances. Foram apenas duas edições do evento organizado pelo movimento estudantil e em nenhuma delas houve a integração entre o que acontecia nos corredores e nas salas de aula, embora tivessem contado na época com o apoio das(os) professoras(es).
} 
Na entrada, uma ficha com apresentação conceitual e informações técnicas sobre as obras, nomes dos/as artistas e da equipe de produção e concepção da mesma foi montada, junto com uma instalação com fotos do making-off do trabalho. Alguns(as) alunos(as) também ocuparam a posição de mediadores da exposição, estando presentes para trocas e diálogos com as os/as visitantes do espaço. A mediação tinha um papel muito importante para todas(os) nós, tendo em vista que preocupava-nos o fato de que o público pudesse debater sobre o processo de produção das obras em sua relação com os produtos ali expostos. Além disso, grande parte das obras, produzidas coletivamente, eram interativas. Elas deveriam ser continuadas por quem visitasse a exposição em um apelo/convite à reflexão e ao deslocamento em relação aos lugares de privilégio, por parte das pessoas brancas, e de um espaço de acolhimento reflexivo por quem reconhecesse seu próprio sofrimento decorrente de questões raciais.

A mesma sala de aula na qual aconteceu a disciplina tornou-se uma galeria. A exposição À flor/cor da pele foi apontada pelos/as seus visitantes como importante espaço de sensibilização quanto ao racismo estrutural e suas formas de construção de realidades racistas, patriarcais e sexonormalizadoras. Nesse sentido, foram importantes os relatos dos/as estudantes que atuaram como mediadores da exposição, interagindo e percebendo as formas como os(as) visitantes reagiam às obras: se interagiam quando convidados/as a isso; se conversavam sobre; se exprimiam emoções como rir ou chorar, percebendo como, para algumas pessoas, os elementos artísticos provocavam deslocamentos e desconfortos quanto a ocupar lugares de privilégio ou de submissão. Trazer esses conteúdos foi uma forma de utilizar a arte e suas linguagens como resistência às opressões e privilégios estabelecidos.

\section{Sobre as obras e seus contextos}

Dentre as obras produzidas em conjunto ou individualmente, estavam aquelas que tinham um componente de abertura para que o público interviesse, e as que não tinham essa proposta. Descreveremos abaixo todas as obras, iniciando pelas que tinham um componente interativo. A intenção de descrição aqui não passa de um exercício 
linguístico, que não escapa a ruídos decorrentes da própria função da linguagem relacional, mas que entendemos como relevante, no sentido de tentar levar a(o) leitora(or) a imaginar-se nesse espaço, e na produção coletiva e processual construída pelos participantes/autores/artistas.

A "manga com leite" tratava da construção de desigualdades raciais, de classe e gênero, a partir da história da avó de uma das autoras, que não deixava sua família comer manga com leite, passando toda sua vida sem ter provado tal combinação. As visitantes eram convidadas a passear por um túnel onde havia mangas, folhas, músicas de cantoras negras e poemas decoloniais, e a história de como esse mito foi criado no período da escravatura no Brasil. Ao final, a visitante podia provar manga com leite.

A obra coletiva "olhares sobre identidades" trazia fotografias e espelhos, em um jogo no qual a visitante podia se ver no meio dessa bricolagem. Ao lado de algumas fotos havia depoimentos sobre a relação entre cor da pele e identidade. Post-its estavam colocados de uma maneira que o público pudesse deixar seu próprio depoimento se desejasse.

A “(trans)lisi-se" trazia em uma mesa com toalha preta, uma secadora modelo chapinha, creme de pentear, flores e cachos. Havia um espaço em uma moldura de retrato com um papel branco dentro, para o público se colocar, caso desejasse.

A obra "abayomis e estêncils" trazia uma cortina de bonecas abayomis, dispostas em uma parede, feitas em uma das aulas da disciplina (aula sobre Psicologia, saúde mental e racismo estrutural). As bonecas carregavam bandeiras com partes da história de sua criação. Abaixo da parede, no solo, havia um pano de algodão com tintas e estêncis ao lado (estes foram feitos em outra das aulas da disciplina, na qual se discutiu sobre “Redução de danos e políticas de drogas na relação com o racismo no Brasil”). As pessoas podiam interagir utilizando os estêncis no pano em forma de painel.

A obra "o que você tira do bolso?", trazia uma camisa branca, pendurada em um cabide no teto, como um coração bordado em um bolso, do qual saiam papéis pendurados em fios vermelhos. Os papéis traziam frases sobre branquitude e privilégios. 
Os mesmos caiam até o chão formando alguns novelos. Ao lado do bolso havia pedacinhos de papel e uma caneta, indicando que o público poderia interagir com a obra.

Nove livros do artista - livros criados e/ou recriados por artistas estavam dispostos pela sala, em uma grande mesa e em pequenas mesas com cadeiras para que as pessoas pudessem sentar e manuseá-los. Havia desde interações com livros existentes ("O pequeno príncipe" de Saint-Exupéry, um livro infantil sobre a boneca Barbie, branca e loura, livros sobre Psicologia etc.) à construção de novos livros. As obras dialogavam com diversas facetas do racismo estrutural: a questão do ideal de beleza branco e nórdico; a questão da identificação com um herói negro nas obras infantis e infanto-juvenis; as relações subjetivas com os sofrimentos que o racismo provoca nas pessoas de pele negra; a branquitude e os privilégios de cor para as pessoas brancas; a questão da ancestralidade e da religiosidade de matriz africana. Nos livros havia a utilização de diversos recursos expressivos: tintas de aguada, giz de cera, colagens, recortes, páginas queimadas com fogo, colagens com areia, folhas de plantas e raízes. Os livros dos(as) artistas tinham como objetivo questionar a construção hegemonicamente branca e europeia da literatura e da ciência. Ao serem realizadas intervenções nos livros “originais", outros livros iam sendo criados, pautados numa construção de saber-poder de resistências.

Dentre as obras não interativas havia: um desenho em cartolina, tinta aguada e giz de cera denunciando o uso indevido de cotas raciais por pessoas de pele branca no curso de graduação em Psicologia esse cartaz foi exposto na parede ao lado de onde haviam sido, anteriormente à própria disciplina, realizas escritas-denúncias sobre a fraude de cotas; um móbile extensivo com vários quadros em tamanho $\mathrm{A} 3$ de reproduções parciais de trechos de violências sofridas por homens jovens e negros pela polícia, em matérias de jornal e revistas que reiteravam como o racismo estrutural, através do extermínio da população negra e pobre, vem sendo mantido no Brasil. Uma outra obra em formato de móbile, em um dos centros da sala de exposição, trazia imagens diversas sobre corpos e sexualidades femininas e queer; e finalmente, um varal em formato de uma grande bandeira LGBTQIA+ trazia imagens de pessoas do curso de Psicologia, relacionando as questões de negritude e branquitude às das sexualidades dissidentes. 
Esses trabalhos, feitos com materiais muito simples e de baixo custo, tinham uma potência maior quando dispostos juntos, em um espaço criado e ambientado para que quem ali entrasse, mergulhasse na experiência de contato com cada uma das obras construídas. Nesse percurso as pessoas foram interagindo com as obras e deixando relatos da experiência com os(as) mediadores(as). A experiência como um todo fez-nos refletir sobre as possibilidades entre ética e estética em suas dimensões de resistência e transformação das realidades. Longe de querermos chegar a alguma conclusão sobre essa relação de impasse, gostaríamos de apontar para a importância desses elementos no processo de discussão sobre o racismo estrutural, e em como o campo Psi e particularmente os espaços de formação são fundamentais para as desconstruções necessárias.

\section{Descolonizando o campo Psi através do debate sobre hierarquizações de} raças e das artes como espaços de resistência

Os deslocamentos promovidos pelas possibilidades de sentir corporalmente os efeitos das teorias e conceitos trabalhados ao longo da disciplina 'Tópicos especiais 1: psicologia, raça e estética como resistência' foram também corporificados (HARAWAY, 1995) em formatos artísticos diversos e tratados como uma intervenção psicossocial artística. Esse processo nos permitiu questionar no cotidiano as realidades concretas (FREIRE, 1999) que se perpetuam no tocante à colonização de corpos e subjetividades em nossa sociedade atual.

Além disso, através das artes-políticas pudemos trabalhar as tensões inter-raciais presentes no decorrer da disciplina. Em muitos momentos, que não só os das visitações extra sala-de-aula sobre as quais discorremos anteriormente, as questões de privilégios de branquitude foram tensionadas. Havíamos programado como uma das temáticas da disciplina as questões de branquitude e branqueamento no Brasil, mas sentimos, junto aos(às) estudantes, a necessidade de dar mais ênfase à essa discussão, perpassando-as por todas as demais temáticas, visto que a branquitude como "suposto" lugar de 
referencial de humanidade e seus privilégios, são a base de sustentação para o racismo e, portanto, o maior empecilho para a superação do mesmo (JESUS, 2017).

Assim, a problematização teórica, os exemplos de privilégios na vida cotidiana e no próprio saber e fazer da Psicologia em conjunto com os recursos artísticos visaram provocar diversos deslocamentos: sair do jogo (pactos) de silenciamento e suposta "neutralidade" frente às posturas racistas e à própria branquitude enquanto identidade racial, a qual visa a manutenção de privilégios (BENTO, 2002); compreender as relações raciais entre branquitude e negritude não apenas como diferenças, mas como desigualdade e hierarquia (PIZA, 2002); desmontar a suposta "superioridade" intelectual e estética como um fundamento da construção da branquitude (SCHUCMAN, 2012). Não podemos de forma alguma afirmar que todas essas experimentações atravessaram os(as) estudantes da disciplina em sua maioria de brancos da mesma maneira, mas pudemos perceber uma crescente criticidade frente à própria racialização, ampliando, como diz Lourenço Cardoso (2017), a capacidade de exercer a autorreflexão, processo essencial para exercer uma branquitude crítica. Vale ressaltar ainda que a desconstruçãoreconstrução da branquitude, em nível individual e coletivo, é um processo constante e sempre em andamento (BENTO, 2002), visto a persistência da colonialidade em nossas estruturas sociais, relações e subjetividades.

As artes e suas relações ético-estético-políticas mostraram-se altamente potentes enquanto possibilidades de experimentar dispositivos analíticos no cotidiano; como possibilidade de tocar e mover processos de subjetivação massificados, normatizados, polarizados e desiguais; de permitir seguirmos com aberturas para processos de resistência e de reconstrução das normas opressoras que mascaram sofrimentos e reiterações de falsas verdades, como a do mito da democracia racial e a da miscigenação das pessoas brasileiras como estratégia de igualdade.

Desmascarar os saberes instituídos é papel das Psicologias e, em sua aproximação com as artes enquanto estéticas da existência (FOUCAULT, 2014), a busca por uma potência de vida humana possível, menos desigual e carregada de privilégios, mais próxima de aberturas solidárias e de construções pautadas nos saberes locais ancestrais e marginalizados, faz-se possível e urgente. Nesse sentido, a opção descolonial 
problematizada por Mignolo (2008) se faz necessária e os processos de desobediência epistêmica ainda mais. Para as epistemes ocidentalizadas, pautadas em divisões/oposições/dicotomias/hierarquias, a arte não se atrela à psicologia e à política; apsicologia não se atrela à arte e à política; a política não diz nada das subjetividades. Ir de encontro à colonialidade presente nessas (o)posições e compreender que arte, psicologia, política e relações raciais podem ser processos imbricados e necessários a insurgências de subjetividades descolonizadas é contrariar a lógica necessariamente eurocentrada e desobedecê-la epistemologicamente. É necessária ainda a consciência de que a opção descolonial não significa o abandono de toda a prática e fundamento euroocidental, visto a não viabilidade disso frente ao forte arraigamento desta em nossas subjetividades. A opção descolonial busca o pensamento de fronteira, o fronteiriço entre as margens e o centro, buscando evitar os fundamentalismos, sejam eles ocidentais ou não ocidentais.

Respiramos política, somos seres políticos, necessitamos de ações que descolonizem nossos olhares cansados (HAN, 2017), em uma sociedade que necessita se reconstruir. Esse é o lugar da formação nas universidades públicas federais e deve ser fortalecido: o de permitir debates interdisciplinares que desloquem os saberes instituídos e as verdades opressoras. As Psicologias, nestes termos, têm muito que beber dos espaços de construção artísticas, e muito o que reconstruir rumo a uma formação não pautada na colonialidade do poder e do saber, nos privilégios da branquitude e nas opressões aos corpos negros.

\section{Referências}

ADRIÃO, Karla Galvão. Feminismo, psicologia e justiça social: um encontro possível? Uma entrevista com Michelle Fine. Psicologia e Sociedade, Belo Horizonte: PUC Minas, v.27, n.3, p. 479-486, 2015.

ADRIÃO, Karla Galvão. Feminismos, arteterapia e psicologias: uma leitura a partir do trabalho em um grupo com mulheres em PE. Artigo apresentado como exigência parcial para obtenção de Titulação em Arteterapeuta. Formação livre. Recife: Traços, 2019. 
BENTO, Maria Aparecida. Branqueamento e branquitude no Brasil. In: CARONE, Iray; BENTO, Maria Aparecida (orgs.). Psicologia social do racismo: estudos sobre branqueamento e branquitude no Brasil. Petropolis: Vozes, 2002. p.25-58.

BOAL, Augusto. Jogos para atores e não-atores. Rio de Janeiro: Civilização Brasileira, 2007.

BOAL, Augusto. A estética do oprimido. Rio de Janeiro: Garamond, 2009.

CARDOSO, Lourenço. A branquitude revisitada e as críticas. In: MULLER, Tânia M. P.; CARDOSO, Lourenço (orgs.). Branquitude: estudos sobre a identidade branca no Brasil. Curitiba: Appris, 2017. p.33-52.

ESTUDANTE 1. [Diário de campo de] Karla Galvão Adrião, Recife (PE), 04 de Setembro de 2018.

FINE, Michele et al. Para quem? Pesquisa qualitativa, representações e responsabilidades sociais. In: DENZIN, Norman K.; LINCOLN, Yvonna S.(orgs.). O planejamento da pesquisa qualitativa: teorias e abordagens. Porto Alegre: Artmed, 2006. p. 115-140.

FOUCAULT, Michel. A história da sexualidade: o cuidado de si. São Paulo: Paz e terra, 2014.

FREIRE, Paulo. Criando métodos de pesquisa alternativa: aprendendo a fazê-la melhor através da ação. In: BRANDÃO, Carlos (org.). Pesquisa participante. São Paulo:

Braziliense, 1999. p.34-41.

GROSFOGUEL, Ramón. A estrutura do conhecimento nas universidades ocidentalizadas: racismo/sexismo epistêmico e os quatro genocídios/epistemicídios do longo século XVI.

Revista Sociedade e Estado, Brasília: UNB, v.31, n.1, p.25-49, jan/abr 2016.

HAN, Byung-Chul. Sociedade do cansaço. 2` ed. amp. Petrópolis: Vozes, 2017.

HARAWAY, Donna. Saberes localizados: a questão da ciência para o feminismo e o privilégio da perspectiva parcial. Cadernos PAGU, Campinas: UNICAMP, n.5, p. 7-41, 1995.

JESUS, Camila Moreira de. A persistência do privilégio da brancura: notas sobre os desafios na construção da luta antirracista. In: MULLER, Tânia M. P.; CARDOSO, Lourenço (orgs.). Branquitude: estudos sobre a identidade branca no Brasil. Curitiba: Appris, 2017. p.69-90.

LOPES, Cristina. Pinto. Memórias da pele: arteterapia como intervenção na depressão. Recife: Libertas Editora, 2012. 
LUGONES, María. Rumo a um feminismo descolonial. Revista Estudos Feministas, Florianópolis: UFSC, v.3, n.22, p. 935-952, 2014.

MCCARTHY, Julie; ADRIÃO, Karla G. ARTPAD: um recurso para teatro, participação e desenvolvimento. [S.I.]: Centre for applied theatre research, 2001.

MEIRA, Isabela de França. Artivismos e corpos dissidentes sexuais: movimentos coletivos de (cri)ações estéticas e políticas de resistência à heteronormatividade em Recife. 2019. Dissertação (Mestrado em Psicologia) -Centro de Filosofia e Ciências Humanas, Universidade Federal de Pernambuco, Recife, 2019.

MIGNOLO, Walter D. Desobediência epistêmica: a opção descolonial e o significado de identidade em política. Cadernos de Letras da UFF, Rio de Janeiro: UFF, n.34, p.287-324, 2008.

NASCIMENTO, Abdias do. O genocídio do negro brasileiro: processo de um racismo mascarado. São Paulo: Perspectiva, 2017.

PHILLIPPINI, Angela. Mas o que é mesmo Arteterapia? Coleção de Revistas de Arteterapia Imagens da Transformação, Rio de Janeiro: Pomar, v.05, p. 01-04, 1998.

PHILLIPPINI, Angela. Grupos em arteterapia: redes criativas para colorir vidas. Rio de Janeiro: Wak, 2011.

PIZA, Edith. Porta de vidro: entrada para a branquitude. In: CARONE, Iray; BENTO, Maria Aparecida (orgs.). Psicologia social do racismo: estudos sobre branqueamento e branquitude no Brasil. Petropolis: Vozes, 2002. p.59-90.

QUIJANO, Aníbal. Colonialidade do poder, eurocentrismo e América Latina. In: LANDER, Edgardo (org.). A colonialidade do saber: eurocentrismo e ciências sociais - perspectivas latino-americanas. Buenos Aires: CLACSO, 2005. p.117-142.

RANCIÈRE, Jacques. Políticas da escrita. 2. ed. São Paulo: Editora 34, 2017.

ROSE, Nicolas. Inventando selfs: psicologia, poder e subjetividade. Petrópolis, Rio de Janeiro: Vozes, 2011.

SANTOS, Alessandro de Oliveira dos; SCHUCMAN, Lia Vainer; MARTINS, Hildeberto Vieira. Breve histórico do pensamento psicológico brasileiro sobre relações étnico-raciais. Psicologia Ciência e Profissão, Brasília: CFP, v.32, p.166-175, 2012.

SCHWARCZ, Lilia Moritz. Nem preto nem branco, muito pelo contrário. São Paulo: Claro Enigma, 2012. 
SCHUCMAN, Lia Vainer. Entre o "encardido", o "branco" e o "branquíssimo": Raça, hierarquia e poder na construção da branquitude paulistana. 2012. Tese (Doutorado em Psicologia). Instituto de Psicologia da Universidade de São Paulo, São Paulo, 2012.

SCHUCMAN, Lia Vainer; MARTINS, Hildeberto Vieira. A psicologia e o discurso racial sobre o negro: do "objeto da ciência” ao sujeito politico. Psicologia: Ciência e Profissão, Brasília: CFP, v.37, p.172-185, 2017.

SCOTT, Joan. Experiência. In: SILVA, Alcione Leite; LAGO, Mara Coelho; RAMOS, Tânia R. Oliveira. Falas de gênero. [Florianópolis]: Editora Mulheres, 1999. p.21-55.

SILVEIRA, Nise da. Imagens do inconsciente. Petrópolis: Vozes, 2015.

SPIVAK, Gayatri. Pode o subalterno falar? Belo Horizonte: Editora UFMG, 2010.

VELHO, Gilberto. Observando o familiar. In: NUNES, Edson de Oliveira (org.). A aventura sociológica: objetividade, paixão, improvise e método na pésquisa social. Rio de Janeiro: Zahar, 1978. p.36-47.

Recebido em: 20/09/2019

Aprovado em: 17/02/2020

Universidade do Estado de Santa Catarina - UDESC

Centro de Ciências Humanas e da Educação - FAED

Revista PerCursos

Volume 20 - Número 44 - Ano 2019 revistapercursos@gmail.com 